\title{
REFEREE'S REVIEW
}

\begin{tabular}{|l|l|}
\hline Program: & Master in International Business \\
\hline Student: & Regina R. Fisiuk \\
\hline Title of thesis: & $\begin{array}{l}\text { Human resource management in successful European multinational enterprises during } \\
\text { the economic crisis }\end{array}$ \\
\hline
\end{tabular}

\begin{tabular}{|c|c|c|c|c|}
\hline $\begin{array}{l}\text { Justification of the topic choice. Accuracy in defining the aim and objectives } \\
\text { of the thesis. Justification of the topic choice; accuracy in defining the aim and tasks of the thesis; } \\
\text { originality of the topic and the extent to which it was covered; alignment of the thesis' topic, aim and } \\
\text { objectives. }\end{array}$ & 5 & 4 & 3 & 2 \\
\hline $\begin{array}{l}\text { Structure and logic of the text flow. Logic of research; full scope of the thesis; alignment of } \\
\text { thesis' structural parts, i.e. theoretical and empirical parts. }\end{array}$ & 5 & 4 & 3 & 2 \\
\hline $\begin{array}{l}\text { Quality of analytical approach and quality of offered solution to the research } \\
\text { objectives. Adequacy of objectives coverage; ability to formulate and convey the research problem; } \\
\text { ability to offer options for its solution; application of the latest trends in relevant research are for the set } \\
\text { objectives. }\end{array}$ & 5 & 4 & 3 & 2 \\
\hline $\begin{array}{l}\text { Quality of data gathering and description. Quality of selecting research tools and methods; } \\
\text { data validity adequacy; adequacy of used data for chosen research tools and methods; completeness and } \\
\text { relevance of the list of references. }\end{array}$ & 5 & 4 & 3 & 2 \\
\hline $\begin{array}{l}\text { Scientific aspect of the thesis. Independent scientific thinking in solving the set } \\
\text { problem/objectives; the extent to which the student contributed to selecting and justifying the research model } \\
\text { (conceptual and/or quantitative), developing methodology/approach to set objectives. }\end{array}$ & 5 & 4 & 3 & 2 \\
\hline $\begin{array}{l}\text { Practical/applied nature of research. Extent to which the theoretical background is related to } \\
\text { the international or Russian managerial practice; development of applied recommendations; justification and } \\
\text { interpretation of the empirical/applied results. }\end{array}$ & 5 & 4 & 3 & 2 \\
\hline $\begin{array}{l}\text { Quality of thesis layout. Layout fulfils the requirements of the Regulations for master thesis } \\
\text { preparation and defense, correct layout of tables, figures, references. }\end{array}$ & 5 & 4 & 3 & 2 \\
\hline
\end{tabular}

Each item above is evaluated on the following scale, as applicable: $5=$ the thesis meets all the requirements, $4=$ the thesis meets almost all the requirements, $3=$ a lot of the requirements are not met in the thesis, $2=$ the thesis does not meet the requirements.

\section{Additional comments:}

Justification of the topic choice. Accuracy in defining the aim and objectives of the thesis.

Subject is actual for management of the companies in emergent market conditions and crisis phenomena in economy. It reflects and identifies the specifics of HRM in successful European MNEs in the context of economic crisis. The purpose and research objectives of theses are formulated clearly and fully correspond to a research subject. The contents of theses covered a subject.

\section{Structure and logic of the text flow.}

Text flow is constructed logically, clearly structured. Theoretical and empirical parts are comparable on volume and alignment

\section{Quality of analytical approach and quality of offered solution to the research objectives.}

The research objective corresponds to the put problem. The formulation of a problem, hypothesis and research questions reflect the research essence.

The extensive literature review of a problem and approaches and gaps in a solution is presented in theses.

Quality of analytical approach and choice of tools of the analysis provided high quality of the proposed solution.

\section{Quality of data gathering and description.}

For achieving the research goal, problems and answering research questions, survey-based secondary data from the EU-EFIGE dataset was used. It provided relevance of sample and validity of results and conclusions of research.

The sample selected for the empirical study consists of 320 multinational enterprises.

For testing the research hypothesis, several variables concerning HRM were selected from the dataset. 


\section{Scientific aspect of the thesis.}

Author showed independence in judgment and the analysis of a problem, a choice of the methods of the date analysis and interpretation of results of research. Very accurate design of research is presented in theses. The combination of conceptual and quantitative approaches in research allowed to develop methodology for installation of the purposes.

The relationship between human resource management characteristics and instruments and performance of multinational enterprises in the crisis period were found.

The results of the study revealed the specific features of human resource management in the most successful multinational enterprises during the economic crisis.

\section{Practical/applied nature of research}

Theoretical background of research is closely connected with the international practice and reflects the main tendencies and achievements in HRM practice in the EU countries. The results of the study revealed the specific features of human resource management in the most successful multinational enterprises during the economic crisis. Based on the results, managerial implications on the implementation of human resource management instruments associated with high performance in the period of crisis were provided and performance indicators for measuring successfulness were revealed.

Quality of thesis layout. Layout fulfils the requirements of the Regulations for master thesis preparation and defense, correct layout of tables, figures, references.

Master thesis of Regina R. Fisiuk_meets the requirements of the Master in International Business program, and according to the reviewer's opinion deserves a/an "excellent (A)" grade, thus the author can be given the desired degree.

Date: 13.06 .2015

\section{Referee: Professor Sofia V. Kosheleva}

